\title{
El prólogo y el primer estásimo de Edipo en Colono: un estudio comparativo
}

\author{
Fernando Pérez Lambás ${ }^{1}$
}

Recibido: 16 de noviembre de 2016 / Aceptado: 2 de diciembre de 2016

Resumen. En este trabajo proponemos un análisis del estásimo primero de la tragedia Edipo en Colono de Sófocles a partir de los versos 16 a 18 del prólogo de la misma obra. La comparación entre ambos pasajes puede ser importante en la medida en que el $\alpha \dot{\lambda} \sigma o \varsigma$ descrito en el prólogo es presentado como un espacio, dramáticamente importante, que se desarrolla poéticamente en el primer estásimo. Ambas descripciones presentan puntos en común que no sólo pueden ayudarnos a entender mejor la naturaleza de este bosque sagrado, sino también evidencian la programación dramática de los susodichos versos prologales.

Palabras clave: $\alpha \hat{\lambda} \sigma o \zeta$; prólogo; estásimo primero; Edipo en Colono.

\section{[en] The prologue and the first stasimon of Oedipus at Colonus: a comparative study}

Abstract. In this paper we analyze the first stasimon of the tragedy Oedipus at Colonus of Sophocles based on the verses 16 to 18 of the prologue. The comparison between both passages may be important in the extent that the $\alpha \lambda \gamma \sigma o \zeta$ described in the prologue is introduced like a place, significant from a dramatic point of view, which is developed poetically in the first stasimon. Both descriptions have several aspects in common that may help us to understand better the nature of this sacred forest and the dramatic purpose of the verses 16-18 of the prologue, which tend to schedule the description of the first stasimon.

Keywords: $\alpha \varkappa \gamma \sigma o \varsigma ;$ prologue; first stasimon; Oedipus at Colonus.

Sumario. 1. Introducción. 2. El canto del ruiseñor: armonía y luto. 3. La vegetación sagrada del ă $\lambda \sigma o \zeta$ : evocaciones y símbolos divinos. 4. Conclusiones.

Cómo citar: Pérez Lambás, F. (2017) El prólogo y el primer estásimo de Edipo en Colono: un estudio comparativo, en Cuadernos de Filología Clásica. Estudios griegos e indoeuropeos 27, 49-63.

\footnotetext{
$1 \quad$ Universitat de València

E-mail: fernando.perez@uv.es
} 


\section{Introducción}

El prólogo es la parte inicial de la tragedia en la cual se presenta, de manera sintética, el programa dramático de la obra en atención a aquellas acciones importantes que, planificadas dentro del mismo prólogo, se desarrollan en los episodios y los cantos corales posteriores ${ }^{2}$. Pero también aparecen en él imágenes y expresiones que, desde un enfoque narratológico, son retomadas en momentos posteriores importantes en la acción dramática ${ }^{3}$. De acuerdo con esta definición del prólogo como aquella parte inicial en la cual se exponen hechos importantes desarrollados con posterioridad (cf. Hulton 1969: 58-59; Roberts 2006: 141), un análisis comparativo entre los versos 16 a 18 del prólogo y el estásimo primero de la tragedia Edipo en Colono de Sófocles podría ser importante para comprobar la manera en que el tragediógrafo presenta en el prólogo un espacio, dramáticamente importante ${ }^{4}$, que le sirve para desarrollar poéticamente el mismo motivo en un canto coral posterior que ha hecho correr ríos de tinta entre los estudiosos. Así, el espacio descrito en el prólogo es presentado de manera sintética mediante imágenes y evocaciones que son retomadas y desarrolladas en el susodicho estásimo. Con esta finalidad, introducimos en primer lugar el prólogo y, en segundo lugar, el estásimo antes de abordar el estudio comparativo entre ambos pasajes.

Por un lado, en los versos del prólogo que analizamos, Antígona describe a su anciano y ciego padre Edipo el lugar al que han llegado. El espacio es presentado como un ö $\lambda \sigma o s$, un bosque sagrado donde reina la paz y la armonía, un locus amoenus donde florece la vegetación y donde se ubican cultos a las divinidades, especialmente

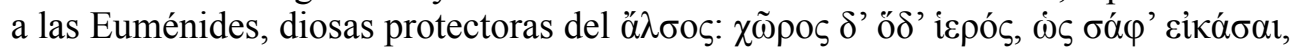

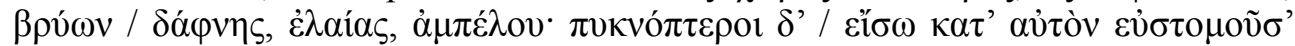

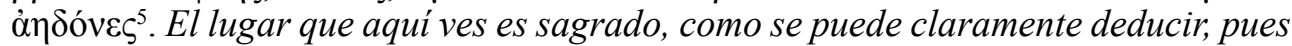
rebosa de laurel, de olivo, de viñedo; y, en su interior, en bandadas aladas entonan

2 El prólogo tiene muchas otras funciones que no podemos analizar en este trabajo. Sus funciones más importantes son dos: presentar el tema de la tragedia y programar las acciones que, a partir del prólogo, se desarrollan en los momentos posteriores. Partiendo de Aristóteles (Po. 1452b 19-20), podemos definir el prólogo como aquella parte unitaria y completa de la tragedia que precede a la párodo o entrada del coro en escena. Con todo, la definición ofrecida por el estagirita parece tener en mente especialmente los prólogos compuestos por Sófocles, pues algunas tragedias de Esquilo, en las que el límite que separa el prólogo de la párodo se encuentra todavía algo difuso, como Persas o Suplicantes, no entrarían dentro de esta clasificación, una cuestión en la que no nos podemos detener. Para una catalogación de las distintas funciones de los prólogos trágicos remitimos a los estudios de Hulton (1969), Schmidt (1971) y Nestle (1967) citados en la bibliografía.

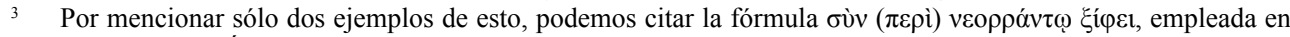
el prólogo de Áyax para referirse al asesinato del ganado y retomada posteriormente en alusión al suicidio del héroe $(A j .30,828)$. También es el caso del «umbral broncíneo», expresión que, en el prólogo de Edipo en Colono, anuncia el lugar donde Edipo va a realizar su tránsito al mundo de los muertos y, al final de la obra, es retomada en el momento en el cual tiene lugar el tránsito efectuado por el héroe (OC. 57, 1590-1591).

4 La descripción del espacio, que la tradición alemana ha denominado la Beschreibung des Ortes, cobra especial relevancia en las últimas tres tragedias conservadas de Sófocles: Electra, Filoctetes y Edipo en Colono. Los prólogos de estas tres tragedias tienen en común la presentación de un lugar, desconocido para ambos personajes o sólo para uno de ellos, por parte de uno de los personajes, que se recrea en una descripción poética del ambiente inicial. En el caso de Edipo en Colono el lugar es un $\alpha \hat{\lambda} \sigma o \varsigma$, un bosque sagrado lleno de cultos y de vegetación adonde el héroe Edipo ha llegado con el fin de acabar su vida y ser enterrado como nuevo héroe benefactor de los atenienses y receptor de culto. Sobre la importancia de la descripción del lugar en estas tragedias, vid. Schmidt 1971: 19; Nestle 1967: 43-45.

5 OC. 16-18. Para el texto griego seguimos la edición de Lloyd-Jones \& Wilson (1990) citada en la bibliografía. Todas las traducciones son personales. 
hermosos trinos los ruiseñores. Es a este lugar sacro al que ha llegado el ciego, anciano y errante Edipo, exiliado de Tebas y guiado por su hija Antígona, con el fin de ser acogido como nuevo héroe protector y benefactor de los atenienses, pues la acción dramática se desarrolla en el bosque sagrado de las Euménides situado en el demo ático de Colono (cf. Bowra 1944: 307-309; Winnington-Ingram 1980: 254255; Segal 1999: 364-365; Birge 1984: 11-12; Wallace 1979: 39-40). Con el objetivo de obtener su recepción como nuevo héroe, Edipo realiza una súplica de hospitalidad a las diosas protectoras del lugar a fin de instalarse y encontrar una $\xi \varepsilon v o ́ \sigma \tau \alpha \sigma 1 \varsigma^{6}$, un alojamiento, y una $\pi \varepsilon ́ p \alpha \sigma i \varsigma ~ \tau o \tilde{v} \beta$ B́ov $^{7}$, un tránsito a su nueva vida en la tumba, desde

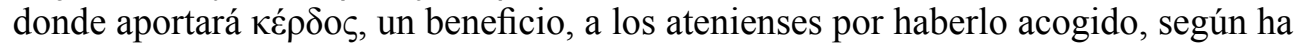
vaticinado el oráculo de Apolo ${ }^{8}$.

Por otro lado, en un momento de decadencia histórica para la Atenas del momento 9 , el estásimo primero de Edipo en Colono, llamado por la tradición «el elogio de Atenas», refleja, en una elaborada ekphrasis, algunos de los símbolos áticos más emblemáticos como distintivos de identidad y de resistencia para los atenienses, como los caballos, la náutica y el olivo (cf. Beer 2004: 160; Rodighiero 2012: 62-64; Burton 1980: 274-275; Gardiner 1987: 113). En este canto se describe el mismo ă $\lambda \sigma o \varsigma$ que en el prólogo, pero esta vez con mayor detalle, pues si al comienzo era una mera presentación del espacio escénico en apenas tres versos, esta nueva descripción aparece más desarrollada y amplificada poéticamente. Ambos pasajes presentan, pues, puntos en común que, como veremos, demuestran la finalidad programática de las palabras descriptivas de Antígona. En este $\ddot{\alpha} \lambda \sigma o \zeta$ florece una frondosa vegetación asociada con cultos que allí tienen lugar, como sucede por norma general en los $\alpha \hat{\lambda} \sigma \eta$, espacios naturales en los que la flora y los cultos aparecen conectados (vid. Birge 1982: 17-21):

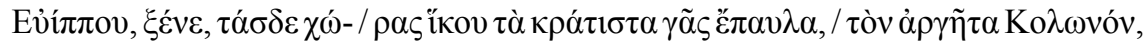

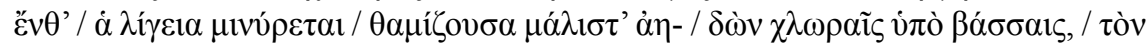

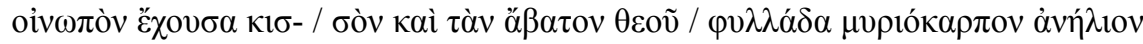

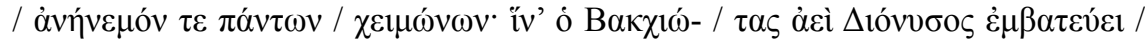
$\theta \varepsilon i ́ \alpha \iota \varsigma \dot{\alpha} \mu \varphi \imath \pi \lambda \tilde{\omega} v \tau \imath \theta \eta \dot{v} \alpha \iota \varsigma^{10}$.

«Has llegado, extranjero, a esta región de bellos caballos, la mejor residencia de la tierra, la blanca Colono, donde el armonioso ruiseñor entona con frecuencia sus trinos entre los verdosos valles, ocupando la hiedra de color del vino y el follaje inaccesible del dios, de incontables frutos, que resguarda el sol y el viento de todo tipo de tempestades. En este lugar siempre penetra el dios báquico, Dioniso, atendiendo a sus divinas nodrizas».

\footnotetext{
OC. 90 .

OC. 103

OC. $86-93$.
}

Edipo en Colono se representó póstumamente en las Grandes Dionisias del año 401 a. C., pocos años después de concluir la guerra del Peloponeso, que, como es bien sabido, supuso la derrota de Atenas y el inicio de su declive.

10 OC. 668-680. Del estásimo que analizamos vamos a centrarnos especialmente en la primera estrofa, que reproducimos en estos versos, $\mathrm{y}$ en la segunda estrofa, que reproduciremos más adelante cuando estudiemos el olivo sagrado. Dejamos de lado la primera y la segunda antistrofas, que sólo mencionaremos cuando sea pertinente para nuestro estudio. 
Como decíamos, la comparación entre los versos 16 a 18 del prólogo y el primer estásimo de la tragedia Edipo en Colono podría confirmar que en ambos pasajes existen puntos en común que demuestran la finalidad programática de las palabras descriptivas de Antígona. Esta primera descripción del espacio escénico es presentada de una manera sintética y reducida, pero es retomada y amplificada poéticamente en el estásimo primero. Así, si al principio Antígona presenta a su padre el lugar al que han llegado mediante un deíctico que señala el espacio escénico, en el estásimo son los coreutas quienes presentan a Edipo el lugar al que éste ha llegado, como muestran el aoristo ǐkov y el vocativo $\xi \varepsilon ́ v \varepsilon$, que se refieren al destinatario de esta descripción. Ambas son, pues, presentaciones del espacio en momentos distintos. En un primer momento, Antígona describe el bosque de manera sucinta aludiendo a los aspectos más distinguidos del mismo, como su sacralidad, su vegetación y los armoniosos ruiseñores. En el canto coral, esta descripción poética se amplifica y se desarrolla en atención a estos tres mismos aspectos, que definen la naturaleza del $\alpha$ $\lambda \sigma o \varsigma$. En concreto, centramos nuestro análisis en dos motivos que creemos importantes para comprender mejor la síntesis descriptiva de las palabras de Antígona: el canto armonioso del ruiseñor y la vegetación sagrada que aparece asociada con las divinidades receptoras de culto en el ó̀ $\sigma \sigma o \varsigma$.

\section{El canto del ruiseñor: armonía y luto}

Tanto en el pasaje del prólogo como en el primer estásimo se menciona al ruiseñor como un pájaro que habita en el interior del $\alpha \hat{\lambda} \sigma o \varsigma$. Su trino es descrito en ambos casos como un canto armonioso y apacible que engalana el paisaje, en el primer momento mediante el verbo $\varepsilon \dot{\sigma} \sigma \tau \mu \varepsilon \dot{\varepsilon} \omega$, que propiamente significa «tener una bella boca», de donde adquiere el significado de «cantar con dulzura» ${ }^{11}$, y en el segundo mediante el adjetivo $\lambda i^{\prime} \gamma \varepsilon 1 \alpha$, referido con frecuencia a un sonido penetrante, agudo, dulce y claro ${ }^{12}$. Con todo, en el mundo griego el canto del ruiseñor no se asocia con la armonía sino con la muerte, pues su canto es paradigma de luto y dolor por el fallecimiento de alguien. Así aparece en los muchos ejemplos en los que el canto del ruiseñor es comparado con los gemidos de dolor que las mujeres proferían en los lamentos fúnebres ${ }^{13}$, así como en algunos mitos griegos, como el de Procne y Filomela y el de Aedón ${ }^{14}$ (vid. Palomar 1999: 59-67).

En esta línea, el verbo $\mu \imath v$ $\rho \varepsilon \sigma \theta \alpha 1$, empleado en el estásimo para designar el canto armonioso del ruiseñor, significa propiamente $\left\langle\right.$ gemir» ${ }^{15}$, de donde se especializa con el sentido de «entonar un canto de dolor»o «tararear una canción» cuya música

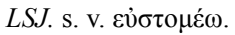

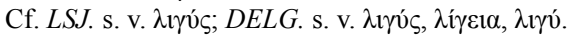

Cf. A. Ag. 1142-1145, Supp. 60-62; S. Aj. 628-631, Tr. 963, El. 107-109, 147-149, 1076-1081.

Sobre el mito de Procne y Filomela, vid. Paus. I 41 8; Ov. Met. VI 412-674. Tereo, rey de Tracia y esposo de Procne, se enamoró de la hermana de ésta Filomela, princesa ateniense, y la violó. Para que no pudiera contar lo sucedido, Tereo cortó la lengua a Filomela y la encerró. Pero ésta consiguió comunicarse con su hermana mediante un lienzo en el que tejió su historia. Cuando Procne se enteró de lo sucedido, para castigar a Tereo descuartizó al hijo de ambos, Ítilo, y se lo sirvió en la comida a su marido. Las hermanas huyeron de la cólera de Tereo y fueron metamorfoseadas. Según versiones, Filomela fue metamorfoseada en golondrina y Procne en ruiseñor $\mathrm{o}$ a la inversa. Esta metamorfosis convierte al ruiseñor en paradigma del canto de luto de la mujer que se lamenta por la muerte de Ítilo. Sobre el mito de Aedón, vid. Hom. Od. XIX 518ss.

15 Cf. Hom. Il. V 889; Od. IV 719.
} 
es más bien nostálgica, referido en este sentido al gorjeo de los pájaros ${ }^{16}$. Pero también el término $\lambda$ íf$_{\varepsilon} 1 \alpha$, aunque con frecuencia se refiera a un canto dulce y claro, en muchos otros casos alude a un sonido triste y melancólico, relacionado con el luto y el lamento fúnebre ${ }^{17}$. De este modo, la ambivalencia semántica del adjetivo

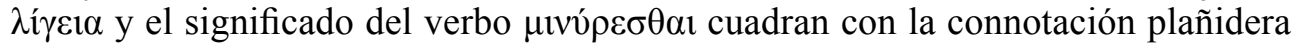
que el canto del ruiseñor tenía en el mundo griego. Por ello, en el cuadro descrito en el estásimo parece establecerse una oposición equilibrada entre la armonía que evoca el canto del ave y la sensación de dolor y de luto que su sonido nostálgico produce.

Así, si el canto del ruiseñor era concebido como un canto fúnebre y plañidero, no es menos cierto que, en contextos paisajísticos como el que aparece en esta tragedia, el sonido del ave parece evocar una oposición equilibrada entre la armonía del locus amoenus y el lamento fúnebre que sugiere el canto. Es con este sentido con el que nos encontramos la alusión al ruiseñor en $\operatorname{Tr} G F$. V 773, 23-26, un pasaje

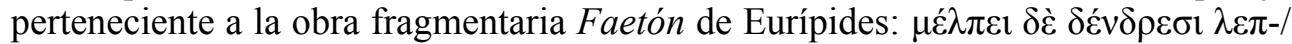

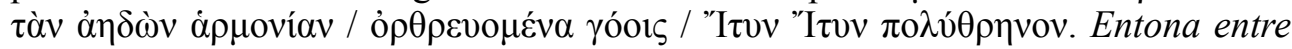
los árboles un ligero y armonioso canto el ruiseñor, que, al alba, se lamenta por Ítilo, por Ítilo muchas veces llorado. En este fragmento se observa claramente la oposición equilibrada entre el luto y la armonía que produce el canto del pájaro en contextos paisajísticos. Así, habitando entre los árboles canta una $\lambda \varepsilon \pi \tau \alpha \grave{\alpha} v \dot{\alpha} \rho \mu o v i ́ \alpha v$ al tiempo que entona su lamento fúnebre por la muerte de Ítilo, personaje que conecta al ruiseñor con el mito de Procne y Filomela. Pero también en el mito de Aedón, transmitido por Homero ${ }^{18}$, se describe al ruiseñor como un pájaro que, posado en la rama, entona un bello canto y, al mismo tiempo, profiere sus gemidos por la muerte de Ítilo.

El ruiseñor, por tanto, según la tradición que retoma Sófocles, habita en los verdes bosques ${ }^{19}$, en las ramas de los árboles y en la vigorosa hiedra ${ }^{20}$, desde donde entona su dulce canto, calificado en alguna ocasión como $\dot{\eta} \delta v \mu \varepsilon \lambda \tilde{\eta}$ y $\lambda \iota \gamma v ́ \varphi \theta o \gamma \gamma o \varsigma^{21}$. Este canto, que forma parte del mismo ambiente natural y armónico que refleja la descripción paisajística ${ }^{22}$, es al mismo tiempo lúgubre y placentero. En este sentido, McDevitt (1972: 231), a propósito de la tragedia que analizamos, ya dejó claro que el ruiseñor «is for the Greeks, and certainly for Sophocles, a powerful symbol of death». Lo mismo sucede con la interpretación de Knox (1964: 155), que se limita a decir que «the nightingale is the bird of lamentation» para concluir que, a causa también de otros elementos que, como veremos, convierten el bosque en un lugar de muerte, en el estásimo se refleja la caída, la muerte y la ruina de Atenas, destruida por los disturbios de la guerra y de las batallas sucedidas en los años anteriores.

16 Cf. A. Ag. 16; Ar. Ec. 880. Sobre el significado de este verbo, vid. Dain \& Mazon 1960: 107; LSJ. s. v. $\mu \mathrm{tvv́ \rho o \mu \alpha l;}$ DELG. s. v. $\mu \mathrm{v} v \rho i ́ \zeta \omega$.

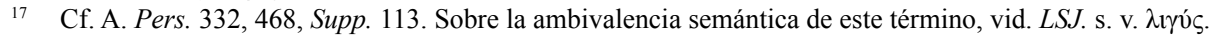

18 Hom. Od. XIX 518ss.

19 Cf. Hom. Od. XIX 518-522; Hes. Op. 203-204. En Hom. Od. XIX 518-522, el canto del ruiseñor es también

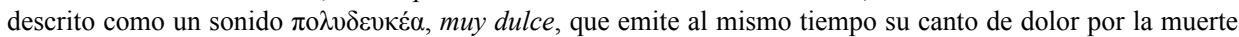
de Ítilo. También en el estásimo que analizamos $(O C .673)$ se dice que el ruiseñor habita entre los verdes valles

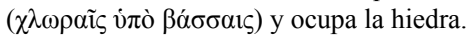

$20 \operatorname{Tr} G F$. V 88, 2.

$21 \quad$ Cf. Ar. Av. 659, 1380-1381; A. Ag. 1146.

22 Hay muchos ejemplos de la relación entre el ruiseñor y los paisajes naturales en Dafnis y Cloe de Longo (I 142 5, I 1823 , II 61 1, III 124 1). 
No obstante, por lo que parece, estos estudiosos no tuvieron presente algunos de los ejemplos que hemos mencionado, de acuerdo con los cuales parece preferible entender el canto del pájaro como un símbolo ambivalente que destaca tanto por la armonía como por el dolor, especialmente en contextos paisajísticos.

Por ello, aunque el paisaje descrito en el prólogo y el estásimo de Edipo en Colono parece remitir a un lugar apacible donde el ruiseñor entona un canto armonioso, la ambivalencia tradicional que el canto de este pájaro presenta y el empleo de términos como $\mu \imath v$ $\rho \varepsilon \sigma \theta \alpha \iota$ y $\lambda$ í $\varepsilon \varepsilon \imath \alpha$ podrían hacernos pensar que, aunque Antígona y el coro describen un paisaje placentero, el bosque se caracteriza también como un lugar de luto y de muerte donde resuena el canto plañidero y apacible del ruiseñor. Así, el mismo ő $\lambda \sigma o \varsigma$ sería un bosque armónico y lúgubre, donde la vida y la muerte aparecen conectados. En este sentido, cabe recordar que en este lugar, en un sitio llamado «el umbral broncíneo» ${ }^{23}$, Edipo va a realizar su tránsito de la vida a la muerte para instalarse como nuevo héroe receptor de culto. De este modo, la sensación de luto que evoca el estásimo podría conectarse con la acción dramática.

En esta línea, las mismas características del bosque, tal como es descrito en el estásimo, están informando de que el ő̀ $\lambda \sigma o \varsigma$ se caracteriza también sutilmente como un lugar de muerte y de luto. Así, en el canto coral se evocan imágenes que aluden al color del bosque en una oposición entrelazada entre la oscuridad y la claridad, que sugiere la idea de que la alegría y la pena, la vida y la muerte, están presentes en el mismo espacio. El lugar al que Edipo ha llegado destaca por la blancura, es la blanca Colono $^{24}$, donde se oculta el ruiseñor bajo los verdosos valles habitando la hiedra «de color oscuro como el vino», oiv $\omega \pi$ ó $^{25}$, y comienza a entonar su dulce y lastimero canto. Es, pues, a este lugar, en el que se contrapone lo armónico y lo lúgubre, al que ha llegado Edipo con el fin de alcanzar el fin de sus días y ser enterrado como nuevo héroe. De este modo, las palabras descriptivas del coro reflejan un ambiente equilibrado y opuesto al mismo tiempo, en el cual la vida y la muerte confluyen.

Pero también las referencias al frondoso bosque, descrito como ó $\beta \alpha \tau o v$,

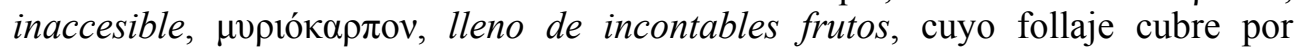

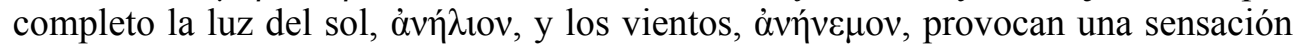
de fertilidad y de aridez al mismo tiempo, un oxímoron que casa perfectamente con la misma oposición entre la vida y la muerte que aparece en el canto coral (vid. McDevitt 1972: 233). Lo mismo sucede con las alusiones a las diosas de los Misterios, Deméter y Perséfone, en la primera antistrofa ${ }^{26}$, así como a las flores del narciso y del azafrán ${ }^{27}$, que presentan claras asociaciones con estas divinidades y con la muerte (cf. McDevitt 1972: 233-234; Knox 1964: 155). Todos estos elementos conectan el bosque con la muerte y lo convierten en un espacio al mismo tiempo armónico y fúnebre, que es presentado al recién llegado Edipo y donde el hijo de Layo realizará su tránsito de la vida a la muerte.

\footnotetext{
OC. $57,1590-1591$.

OC. 670 .

OC. $673-675$.

OC. $681-693$.

$O C$. 681-685. El narciso fue la flor que estaba recolectando Perséfone en el momento en que se abrió la tierra y fue raptada por Hades. Por tanto, es una flor relacionada con la muerte. El azafrán era plantado en las tumbas. Asimismo, en las Tesmoforias, festividad ateniense en honor de las dos diosas, las mujeres se ponían vestidos teñidos de color de azafrán (Ar. Th. 138). Sobre estas dos flores, vid. Jebb 1885: 115-116; Knox 1964: 155; Wallace 1979: 47.
} 
En este proceso de transformación experimentado por el héroe, como podemos comprobar, cobra una especial relevancia la sacralidad del lugar donde transcurre la acción. Este bosque sagrado, en el cual reciben culto las diosas Venerables, presenta características que, al final de la tragedia, serán aplicadas tanto a Edipo como a la tumba donde el nuevo héroe recibirá su culto colectivo como protector de los atenienses. Ambos son espacios fuertemente sagrados, presentados mediante el énfasis inicial del término $\chi \tilde{\omega} \rho \varsigma_{\zeta}$, que describe en el prólogo el bosque y al final el lugar donde Edipo va a desaparecer hacia su nueva vida en la tumba ${ }^{28}$. Tanto el $\alpha \hat{\alpha} \sigma o \varsigma$ como el propio Edipo en el momento de su partida son intocables, $\alpha \theta_{1 \kappa \tau o t^{29}}$, debido a la fuerte sacralidad que rodea tanto el bosque, consagrado a las Euménides, como la tumba, donde Edipo recibirá su culto. Asimismo, el «umbral broncíneo» donde se encuentra Edipo al comienzo de la tragedia anticipa el pasaje que deberá franquear cuando se dirija a su nueva condición de héroe protector al final de la obra ${ }^{30}$. De este modo, la sacralidad del bosque programa también la posterior transformación heroica de Edipo. El contraste entre lo armónico y lo fúnebre no sólo refuerza esta sacralidad, sino también evoca de manera clara la muerte sacralizada del protagonista.

En definitiva, si retomamos la comparación entre los versos 16 a 18 del prólogo y el estásimo primero de Edipo en Colono, podemos afirmar que en ambos casos se describe un $\alpha \lambda \sigma o \varsigma$ en cuyo interior habitan y entonan su canto los ruiseñores. Pero si en el prólogo este canto parece ser armonioso y placentero, en el primer estásimo, momento en el cual se retoma y se desarrolla ampliamente este mismo motivo, este canto se caracteriza por la oposición y la ambivalencia entre lo armonioso y lo

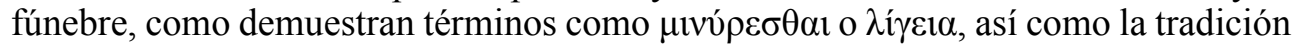
griega anterior a esta tragedia, que presenta al ruiseñor en contextos paisajísticos entonando su canto en un equilibrio contrapuesto entre lo armónico y lo lúgubre, o las oposiciones entre la claridad y la oscuridad, o las alusiones a las dioses Deméter y Perséfone o a las flores del narciso y el azafrán. Todo ello refleja un bosque apacible y agradable, pero también mortuorio, donde Edipo ha llegado para transitar hacia su nueva vida en la muerte. De este modo, las características que definen el ó $\lambda \sigma o \varsigma$ son importantes no sólo por su finalidad descriptiva del espacio sino también por su relación con la acción dramática, de acuerdo con la cual Edipo ha llegado a un espacio en el que confluye el límite que separa la vida de la muerte en una equilibrada oposición. Así, las tres líneas del prólogo, en las que se describía de manera sintética el espacio escénico, se desarrollan con mayor intensidad en el estásimo primero en relación con el motivo tradicional del canto del ruiseñor y con la caracterización del

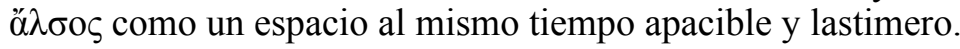

\section{La vegetación sagrada del ở $\sigma o c$ : evocaciones y símbolos divinos}

El ambiente descrito, tanto en el prólogo como en el primer estásimo, se caracteriza por la presencia de una abundante y frondosa flora, que brota de la tierra en un proceso recordado en ambos pasajes. En la descripción del prólogo, este proceso es descrito mediante el verbo $\beta \rho v ́ \omega$, cuyo significado técnico, referido a las plantas, es el

\footnotetext{
Cf. $O C .16,54,1520,1540$.

Cf. $O C .39,1521$.

Cf. OC. $57,1590-1591$.
} 
de «swell or teem with» y «to be full of», con dativo y genitivo respectivamente ${ }^{31}$. El término se aplica, pues, a las plantas que brotan o florecen en abundancia ${ }^{32}$, como adecuadamente observa Kamerbeek (1980: 27). La imagen sugerida es, por tanto, la de las plantas brotando de la tierra, que, en consecuencia, rebosa de laurel, olivo y viñedo, las tres plantas descritas en el prólogo. Por otra parte, en el estásimo primero la abundancia de vegetación se sugiere mediante el compuesto $\mu$ pıóк $\alpha \rho \pi$, que no sólo alude a las tres plantas que aparecían en el prólogo, sino también a toda clase de frutos. La misma idea se recuerda mediante la expresión $\beta \lambda \alpha \sigma \tau o ̀ v ~ \varphi v ́ \tau \varepsilon v \mu \alpha$, referida en la segunda estrofa al olivo sagrado que brota de la tierra y cubre por completo todo el mundo conocido ${ }^{33}$. La amplificación del primer estásimo con respecto al prólogo llega a tal punto que todo este follaje es descrito como una abundante vegetación que envuelve la tierra en su totalidad, sin dejar penetrar la luz del sol ni los vientos, como

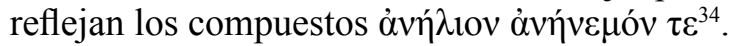

Una prueba de que la descripción del prólogo es retomada y amplificada en el primer estásimo es la alusión a las tres plantas del primer pasaje, dos de las cuales son recordadas también por el coro. De este modo, la vegetación que aparece descrita en el estásimo no sólo se extiende a todo tipo de frutos, frente a las tres plantas del prólogo, sino también se desarrolla en relación con dos de estas mismas plantas, que aparecen asociadas a las divinidades que las representan en el plano simbólico. Por esta razón, aunque en el prólogo no se mencione, podríamos pensar que las tres plantas aludidas, el laurel, el olivo y la viña, también están recordando a sus dioses respectivos, una interpretación que pasan por alto los comentarios (cf. Jebb 1885: 14; Kamerbeek 1980: 27).

A este respecto cabe recordar que la acción dramática tiene lugar en un ón $\sigma 0 \varsigma$, un paisaje agreste de naturaleza sagrada debido a los cultos que allí se desarrollan y a la vegetación que allí florece. En esta línea, no sólo en los ő $\lambda \sigma \eta$ sino en general en muchos cultos y ritos griegos, la vegetación y los dioses aparecen conectados. Así, muchos cultos se pueden explicar por el paisaje natural que rodea el templo o por un símbolo vegetal y sagrado que caracteriza a la divinidad, así como por su relación con la naturaleza, los ríos, los árboles y las montañas (cf. Birge 1982: 17-21; Burkert 2007: 117-118; Mauduit 1988: 306). Por mencionar sólo algunos ejemplos, podemos citar la importancia que tenía el roble sagrado en el santuario de Dodona, así como el paisaje natural de Potnia, que rodeaba un famoso culto en honor de Deméter y Perséfone ${ }^{35}$, el santuario de Apolo en Delfos, rodeado de montañas, el río que fluía en torno al templo de Atenea Saítide en el monte Pontino ${ }^{36}$ o los muchos templos en honor de Poseidón que estaban asociados al agua, al mar, a la fertilidad y a los árboles ${ }^{37}$. De este modo, el paisaje natural, alejado de la mano del hombre, es inseparable de las fuerzas de la naturaleza, que deben estar en contacto con los cultos en honor de los dioses ${ }^{38}$. Pero el $\alpha ̋ \lambda \sigma o \varsigma$ de la tragedia que analizamos no sólo refleja

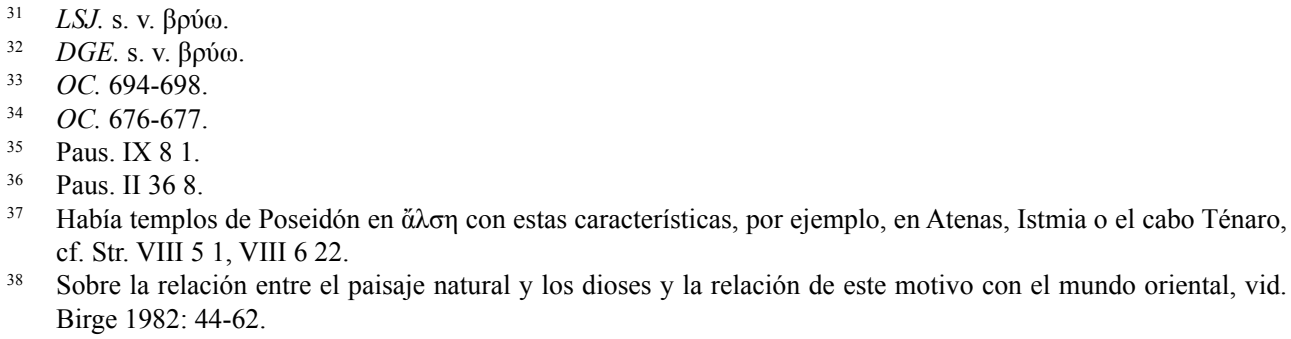

38 Sobre la relación entre el paisaje natural y los dioses y la relación de este motivo con el mundo oriental, vid. Birge 1982: 44-62. 
la naturaleza sagrada del lugar sino también la relación existente entre la vegetación y los cultos que allí tienen lugar ${ }^{39}$. Por este motivo, pensamos que las tres plantas que aparecen en el prólogo, por el simple hecho de formar parte de este espacio natural y sacro, podrían estar recordando a sus divinidades respectivas. De hecho, como veremos, dos de estas plantas son retomadas en el primer estásimo y aparecen desarrolladas y asociadas a sus dioses correspondientes.

En esta línea, el laurel que se menciona en el prólogo estaría recordando a Apolo por ser su símbolo más representativo y aparecer asociado con la divinidad en muchos cultos. Tal es el caso de las Dafneforías, festividad religiosa tebana en honor de Apolo, cuyo nombre se refiere a la procesión en la cual se transportaba el laurel sagrado del dios, venerado entre los tebanos como Apolo Dafneforo (vid. Burkert 2007: 138). Pero también en las Targelias atenienses se transportaba un ramo de

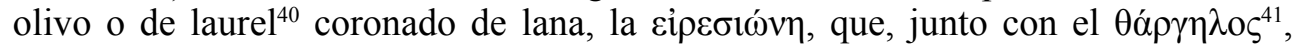
se depositaba en el altar de Apolo con el fin de suplicarle que alejara los males de la comunidad (vid. Parke 1986: 147). Lo mismo sucede con el mito de Dafne, metamorfoseada en laurel al intentar ser violentada por $\mathrm{Apolo}^{42}$. El laurel, por tanto, aparece asociado con el dios Apolo en el mundo religioso griego, razón por la cual tal asociación no podría pasar desapercibida a los espectadores, que oyen hablar de

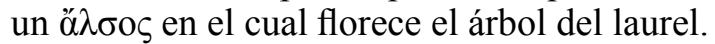

Si el laurel recuerda a Apolo, la viña mencionada en el prólogo remite a Dioniso, que se presenta como una divinidad extranjera que, tras su llegada a Grecia, instala su culto y proporciona el vino a los humanos (vid. Burkert 2007: 218-226). Así aparece la divinidad en muchos mitos en los que Dioniso enseña a los humanos el arte de cultivar la viña y prensar el vino, símbolos asociados de manera directa con el dios ${ }^{43}$. Esta conexión se encuentra presente, por ejemplo, en el mito de Icario, un campesino ateniense a quien Dioniso enseñó por primera vez el arte de crear el vino. Este campesino emborrachó a sus pastores, que lo asesinaron en la creencia de que Icario los había envenenado ${ }^{44}$. Este mito, a su vez, aparece vinculado con las

39 El $\alpha \lambda \lambda \sigma o \varsigma$ estaba por definición consagrado a una divinidad, cf. Od. VI 291, IX 200-201, X 509, XX 278; Hdt. II 138, IX 65; E. $H F$. 615. Sobre esto, vid. $D G E$. s. v. ö $\lambda \sigma o \varsigma$.

40 La mayoría de las fuentes explican que el ramo que se transportaba durante las Targelias estaba hecho de olivo

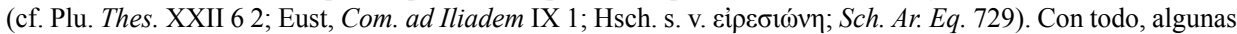

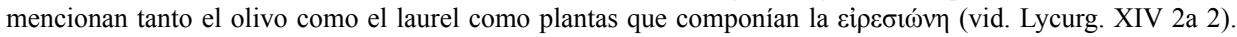
Quizá la alusión al laurel que mencionan algunas fuentes se explique por la relación existente entre el árbol

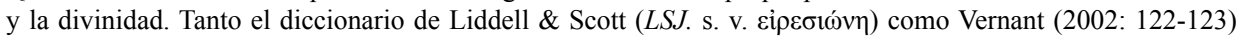
mencionan simplemente que se trataba de un ramo «de laurel o de olivo». En todo caso, debemos subrayar la importancia de la asociación entre el ramo, símbolo vegetal, y la divinidad en una festividad en la que se ofrendaban a la divinidad los primeros frutos de la tierra. Sobre las Targelias, vid. Parke 1986: 146-149.

${ }^{4}$ El $\theta \alpha ́ \rho \gamma \eta \lambda o \varsigma$ era una vasija que contenía las primicias del año y se depositaba en el altar de Apolo como ofrenda al dios, a quien se suplicaba que hiciera cesar la hambruna y la peste de la comunidad, vid. Parke 1986: 147.

42 Ov. Met. I 452-567.

43 Podemos pensar en los muchos mitos griegos en los cuales un rey se opone a introducir en la comunidad el culto de Dioniso. En consecuencia, el dios castiga al pueblo con la locura divina hasta que el culto es finalmente introducido. Junto con su culto, la divinidad incorpora la vid a la vida de los hombres, les enseña el arte de cultivar la viña y prensar el vino. Tal es el caso del rey Penteo de Tebas, tema central de Las Bacantes de Eurípides, Licurgo de Tracia o las Prétides en Argos. Sobre esto, vid. Burkert 2007: 222-223. A este respecto, tampoco debemos olvidar la abundante iconografía que hay del dios rodeado de un racimo de uva.

44 En el origen de este mito está la instauración del culto de Icario y Erígone. Ésta, hija del primero, encontró el cuerpo sin vida de su padre y se ahorcó. En consecuencia, el dios Dioniso castigó a los atenienses con una plaga infundiendo la locura en todas las mujeres, que terminaron ahorcándose. La plaga no cesó hasta que los atenienses instauraron el culto de Icario y Erígone. Sobre esto, vid. Burkert 2007: 221. 
Antesterias, festividad ateniense en honor de Dioniso durante la cual se procedía a la apertura de las jarras y a la introducción del nuevo vino (Burkert 2007: 318). Pero si en el prólogo aparece la viña, en el canto coral se alude a la hiedra, un símbolo vegetal también asociado con Dioniso, a quien se le representa con frecuencia coronado con esta planta ${ }^{45}$.

Con respecto a la tragedia que nos ocupa, aunque en el prólogo no se mencione esta relación entre el dios y el árbol, en el estásimo primero aparece de manera expresa la hiedra como un vegetal que forma parte del $\alpha \lambda \lambda \sigma o \zeta \mathrm{y}$, esta vez de manera clara, se encuentra asociada con Dioniso. Así, la misma hiedra, habitada por el ruiseñor en los verdosos valles del bosque, recibe el epíteto oiv $\omega \pi$ óv, que propiamente significa «del color del vino» ${ }^{46}$, un sentido que directamente relaciona el símbolo vegetal con Dioniso. Asimismo, la asociación entre el dios y el bosque sagrado se hace todavía más evidente en el momento en el que se menciona al ruiseñor como habitante, no

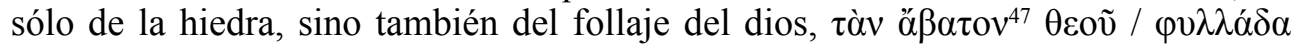
$\mu \nu \rho ı ́ \kappa \alpha \rho \pi \mathrm{ov}$. El follaje del dios y la oscura hiedra se encuentran coordinados y se presentan como habitáculos del ruiseñor. En esta expresión, el genitivo singular $\theta \varepsilon \circ 0 \tilde{v}$ indica la pertenencia del $\alpha \ddot{\lambda} \sigma o \zeta$ a Dioniso ${ }^{48}$, que se introduce en este lugar instalando su nuevo culto, como indican los términos ĩv $\alpha$ y $\varepsilon \mu \beta \alpha \tau \varepsilon v ́ \varepsilon ı$ (cf. Jebb 1885: 114; Saïd 2012: 87). De este modo, en este estásimo se está relacionando de manera clara a la divinidad con un símbolo vegetal, la hiedra, que la representa, al mismo tiempo que se indica que la divinidad recibe culto en el interior del ö $\lambda \sigma o s$. Así, de nuevo en la alusión a la viña observamos que, mientras que en el prólogo aparecía con la simple referencia a la planta que forma parte de este $\alpha ̋ \sigma \sigma o \varsigma$, en el estásimo se desarrolla en su relación con el dios Dioniso, asociado de manera directa con su símbolo vegetal. En efecto, los componentes principales del bosque sagrado, la flora y los cultos, aparecen de nuevo formando parte de este paisaje y conectados entre sí.

Después del laurel y la viña, encontramos el olivo, que podría estar recordando a Atenea, pues la planta y la deidad aparecen asociados con frecuencia. Esta asociación no sólo relaciona el olivo con su correspondiente divinidad sino también con la polis de los atenienses, para quienes uno de los símbolos sagrados más emblemáticos era precisamente el olivo. No podemos dejar de mencionar el olivo que la diosa regaló a Atenas en su lucha contra Poseidón por la soberanía de la comunidad, tras lo cual el olivo sagrado se depositó en el Erecteion como símbolo de identidad entre los atenienses (Knox 1964: 154). Asimismo, durante las Panateneas, festividad principal ateniense en honor de la diosa Atenea, una rama de olivo era transportada en procesión por los $\Theta \alpha \lambda \lambda$ opópol, ancianos encargados de llevar el $\theta \alpha \lambda \lambda$ ó $\varsigma$ (Parke 1986: 44). Resulta, pues, evidente la conexión entre Atenas, su divinidad protectora Atenea y el olivo.

45 Cf. E. Ba. 81-82; Ar. Th. 999-1000.

46 LSJ. s. v. oivwiós.

47 El término $\alpha \beta \alpha \tau o v$, en el cual no podemos adentrarnos, refleja también una fuerte sacralidad en el espacio descrito. Etimológicamente, el término significa «not to be trodden» ( $L S J$. s. v. $\alpha \beta \alpha \tau o \varsigma)$ y presenta una frecuencia de uso muy elevada en relación con espacios fuertemente sagrados y prohibidos, reservados a la divinidad y

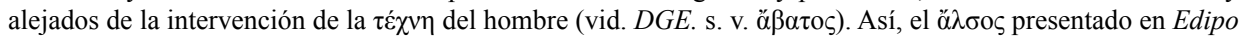

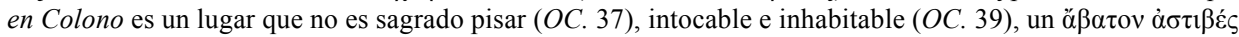
(cf. $O C .126,167,675)$, donde la mano del hombre tiene prohibido el acceso (OC. 19, 101). Sobre esto, vid. Jouanna 1995: 39-40; Mauduit 1988: 306; Saïd 2012: 85-86.

48 Las distintas divinidades que aparecen en el estásimo reflejan la conexión entre el $\alpha \varkappa \sigma o \varsigma$ y la Academia de Atenas, donde Dioniso, Eros y las Musas recibían culto (cf. Paus. I 29 1, I 30 1-2). Sobre esto, vid. Saïd $2012: 87$. 
Si analizamos ahora la tragedia que nos ocupa, mientras que en el prólogo sólo se menciona el olivo como una planta que crece dentro del $\alpha \hat{\lambda} \sigma o \varsigma$, en el primer estásimo se dedica la segunda estrofa entera al olivo en un claro elogio de uno de los símbolos más identificativos de los atenienses y que forma parte de este bosque:

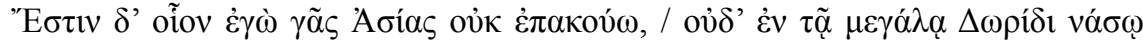

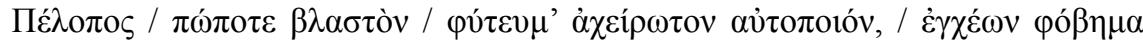

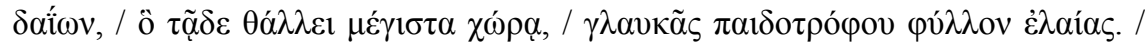

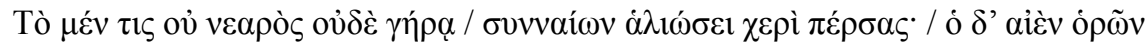

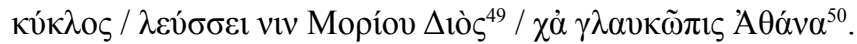

«No existe árbol alguno que yo haya escuchado que nunca haya brotado, ni en la tierra de Asia, ni en la gran isla doria de Pélope, inconquistable, que se autogenera, temor de las espadas enemigas, que florece en abundancia en esta región: la hoja del glauco olivo que nutre a nuestros hijos. A éste nadie, ni un joven ni quien se encuentra en la vejez, podría capturarlo tomándolo por la fuerza; pues lo observa el ojo siempre vigilante de Zeus Protector de los olivos y Atenea la de ojos glaucos.»

Como podemos comprobar por el pasaje citado, tras una extensa amplificación en la que se introduce una planta, $\varphi v ́ \tau \varepsilon v \mu \alpha$, todavía sin mencionar, que se extiende en abundancia en este bosque y es elogiada como la más resistente e indestructible planta del mundo conocido, se menciona, en un verso entero y con una sobrecarga de epítetos, el olivo sagrado que se extiende en el ó $\lambda \sigma o s$. La disposición estilística es, por tanto, importante en la medida en que se concede énfasis al símbolo sagrado. Esta planta retoma la alusión al olivo que, en el prólogo, aparecía en referencia al árbol que crecía en el interior del lugar. Pero ahora este símbolo vegetal se desarrolla y se menciona como un símbolo de resistencia e identidad para los atenienses. Así, el mismo olivo es descrito como «el temor de las espadas enemigas», es calificado

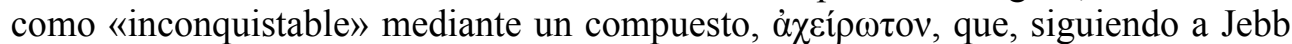
(1885: 118), debido al contexto en el que aparece podría referirse propiamente a

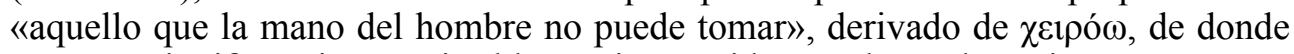
pasaría a significar «inconquistable», único sentido con el que el término se encuentra

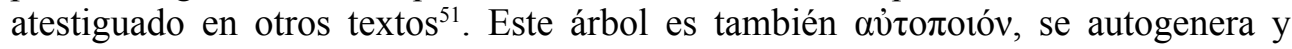

49 Sobre Zeus Morio, cuyo epíteto especifica la esfera de acción de este dios como protector de los olivos, vid. Jebb 1885: 120. Cabe decir que, además de los olivos como propiedad privada (Lys. Or. 7, 10), existían olivos públicos que eran propiedad del Estado. Estos últimos eran llamados Mopíal, pues según la leyenda habían sido propagados ( $\mu \varepsilon \mu \mathrm{o} \rho \eta \mu \varepsilon ́ v \alpha$ ) a partir del olivo original que Atenea había hecho crecer en la Acrópolis. Estos olivos, al concederles carácter sagrado a causa de su proveniencia, estaban bajo el cuidado del Areópago y debían ser inspeccionados mensualmente. Por ello, arrancar una $\mu$ opía era un sacrilegio y se castigaba con la confiscación de los bienes, pues estos olivos públicos estaban protegidos por Zsùৎ Mópıৎ.

50 OC. 694-706.

51 El compuesto $\dot{\alpha} \chi \varepsilon i ́ p \omega \tau$ tov también podría referirse a una planta que no ha sido cultivada por la mano del hombre

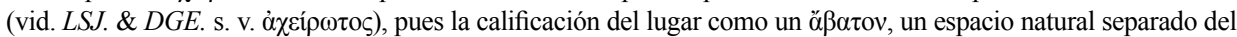
hombre y, por tanto, sagrado en sí mismo, cuadraría perfectamente con este sentido. Ésta es la explicación que da

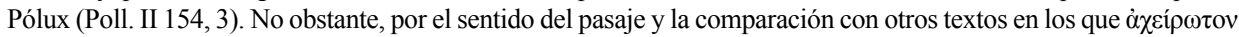
significa «inconquistable» (vid. Th. VI 10), nos inclinamos por este último significado, pues de otro modo sería el único pasaje en el que el término tendría el sentido de «incultivable». Sobre esto, vid. Jebb 1885: 118; Burton

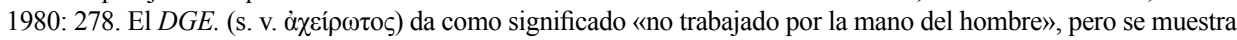
incrédulo en la medida en que, entre paréntesis, matiza que quizá tenga el primer significado de «inconquistable». 
nunca se destruye, una calificación que podría recordar el episodio, transmitido por Heródoto $^{52}$, según el cual el olivo sagrado que se encontraba en la Acrópolis fue quemado por los persas y, al día siguiente, volvió a brotar (cf. Burton 1980: 276; Saïd 2012: 87). El olivo, por tanto, se presenta como el árbol más resistente del mundo conocido, desde Asia al Peloponeso, un símbolo de resistencia que asegura el aguante de la región del Ática en un momento histórico en el que Atenas se encontraba sacudida por los disturbios de la guerra del Peloponeso, finalizada pocos años antes de que se representara Edipo en Colono (cf. Burton 1980: 275-276; Knox 1964: 155-156).

Al mismo tiempo, la importancia del olivo no sólo radica en su calificación como símbolo de identidad y resistencia para los atenienses, sino también por su relación con la diosa Atenea, protectora de la comunidad. Así, aunque esta conexión no aparezca de manera explícita en el prólogo, en el estásimo se encuentra presente. De hecho, tanto la planta como la divinidad reciben el epíteto $\gamma \lambda \alpha v \kappa o ́ \varsigma$, que evidencia esta conexión. El olivo indestructible, situado en la Acrópolis, es vigilado por Zeus Morio, protector de los olivos, y por Atenea la de ojos glaucos. En posición enfática al final de verso se menciona a la deidad protectora de la ciudad mediante un epíteto tradicional y bien conocido de la diosa: Г $\lambda \alpha v \kappa \tilde{\omega} \pi ı \varsigma$. El compuesto podría recordar el registro elevado de Homero ${ }^{53}$, pero en un nuevo contexto. En este pasaje, la diosa Atenea se identifica con el olivo sagrado de su comunidad, asociados ambos por un mismo epíteto, pues el compuesto $\gamma \lambda \alpha \nu \kappa \tilde{\omega} \pi \iota \varsigma$ referido a Atenea en el último verso está retomando el calificativo $\gamma \lambda \alpha v \kappa \tilde{\alpha} \varsigma$ que unos versos antes aludía al olivo, planta que sirve de alimento a los niños de la comunidad ${ }^{54}$. La Atenea homérica, por tanto, se presenta esta vez como la protectora de los atenienses, vigilante del olivo como símbolo vegetal que la representa en el interior de este ő $\lambda \sigma o \varsigma$. Esta conexión entre la diosa y su símbolo vegetal, que se encuentra bastante clara en el estásimo, parece sugerirse en el prólogo mediante la simple alusión al olivo que brota dentro de este lugar sacro, como sucedía también con el laurel con respecto a Apolo y con la viña en relación con Dioniso.

52 Hdt. VIII 55.

53 Cf. Hom. Il. I 206, II 166, II 172, II 279, II 446, IV 439, V 29, V 133, V 405, V 420, V 719, V 825, V 853, VII 17, VII 33, VII 43, VIII 30, VIII 357, X 482, X 553, XVII 567, XVIII 227, XX 69, XXII 177, XXII 214 , XXII 238, XXII 446; Hom. Od. I 44, I 80, I 178, I 221, I 314, I 319, I 364, II 382, II 393, II 399, II 420, III 13, III 25, III 218, III 229, III 330, III 356, III 371, IV 795, V 427, V 437, VI 13, VI 24, VI 41, VI 47, VI 112 , VII 19, VII 27, VII 47, VII 78, XI 626, XIII 236, XIII 287, XIII 329, XIII 361, XIII 374, XIII 392, XIII 420, XV 9, XV 292, XVI 451, XVIII 158, XVIII 187, XIX 604, XX 44, XXI 1, XXI 358, XXIII 242, XXIII 344, XXIV 516, XXIV 541.

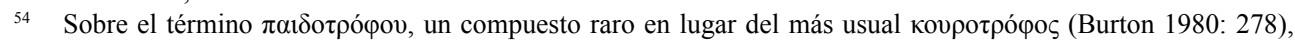
referido al olivo se han dado diversas interpretaciones. Según Jebb (1885: 119), el compuesto podría recordar a las diosas de los Misterios, mencionadas unos versos antes, pues en las Tesmoforias las diosas eran asociadas

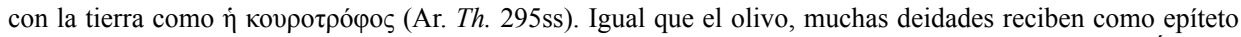

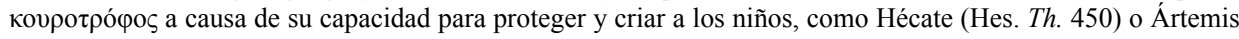
(D. S. V 73). Por su parte, Knox (1964: 154-155) analiza este compuesto en su sentido literal, explicando que del olivo se extrae el aceite, el principal producto que se exportaba de Atenas y se extendía por todo el Mediterráneo. Si damos crédito a esta interpretación, el olivo sería uno de los principales productos de la comida mediterránea y alimento de los niños. Por otro lado, podríamos ver en el compuesto una alusión a la costumbre

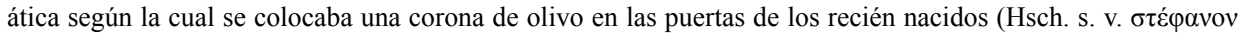

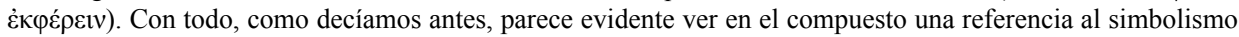
religioso de la коvротрофía extendido al conjunto de los atenienses, pues el olivo no sólo es alimento de los niños sino también de la comunidad. 


\section{Conclusiones}

En este trabajo, creemos haber puesto de manifiesto que, entre los versos 16 a 18 del prólogo y el estásimo primero de la tragedia Edipo en Colono, existen algunos puntos en común que confirman la importancia del prólogo como una parte de la tragedia en la cual se presentan de manera sucinta algunos aspectos importantes que posteriormente se van a desarrollar.

En los dos pasajes analizados se describe un ó̉ $\sigma 0 \varsigma$, de manera sintética en el prólogo y con una clara amplificación poética en el primer estásimo. Este bosque se caracteriza por una fuerte sacralidad mencionada en el prólogo y explicada con mayor detalle en el canto coral. Esta sacralidad deriva de los animales, las plantas y los cultos que se encuentran en el interior del lugar. En ambos pasajes se menciona al ruiseñor como un pájaro que habita en el $\alpha \lambda \sigma o \varsigma$ y engalana el paisaje con un canto que es a la vez armonioso y plañidero.

Así pues, este canto es presentado en el prólogo mediante un verbo que evoca la armonía que se respira en el interior del bosque. Con todo, en el estásimo la sensación armoniosa del canto es matizada, pues se trata de un trino que también presenta rasgos mortuorios, que convierten el bosque en un lugar no sólo apacible sino también lúgubre y fúnebre, en el cual Edipo ha de realizar el tránsito hacia su nueva vida en la muerte, como demuestran la tradición retomada por Sófocles y los elementos lingüísticos que describen el canto. Esta ambivalencia del canto del ruiseñor, al mismo tiempo armonioso y lúgubre, presenta el espacio en una equilibrada oposición entre la vida y la muerte, la alegría y la tristeza, una característica del $\alpha ̋ \lambda \sigma o \varsigma$ que conecta el estásimo con la acción dramática y programa la transformación heroica de Edipo.

Asimismo, tanto en el prólogo como en el estásimo se evoca la imagen de una frondosa vegetación que brota de la tierra, armoniza el paisaje y cubre por completo el terreno. Este proceso es descrito en el prólogo mediante el verbo $\beta \rho v ́ \omega$, que sólo se refiere a tres árboles concretos, y en el estásimo mediante términos como $\mu v \rho ı ́ \kappa \alpha \rho \pi \circ v$ o $\beta \lambda \alpha \sigma \tau o ̀ v ~ \varphi v ́ \tau \varepsilon v \mu \alpha$, que no sólo aluden al olivo sagrado sino también a toda clase de frutos. De este modo, la vegetación se amplía de manera considerable en el canto coral. Pero también, en relación con las tres plantas que aparecen en el prólogo, por la naturaleza sagrada del espacio en el que se encuentran y sus frecuentes asociaciones con divinidades concretas, podríamos pensar, aunque en el prólogo no se mencione de manera expresa, que en realidad están recordando a las tres divinidades que las representan, de modo que estos tres árboles serían en sí mismos también sagrados.

Así pues, el laurel estaría recordando al dios Apolo, el olivo a Atenea y la viña a Dioniso. Una prueba de tal asociación la podemos encontrar en que dos de estas plantas aparecen recordadas y amplificadas en el estásimo, asociadas de manera directa con sus respectivas deidades. La viña del prólogo aparece en el estásimo como la hiedra, que se presenta como símbolo vegetal asociado de manera clara con Dioniso, divinidad que introduce su culto en este lugar sacro. Del mismo modo, en el estásimo el olivo se encuentra claramente asimilado a la diosa Atenea, como un símbolo de resistencia e identidad para los atenienses, cuya divinidad protectora se encuentra así conectada con el espacio sagrado en el que tiene lugar la acción dramática de Edipo en Colono. 


\section{Bibliografía}

\section{Ediciones y comentarios}

Dain, Alphonse \& Mazon, Paul (1960), Sophocle: Philoctète, Edipe à Colone, vol 3. Paris. Jebb, Richard Claverhouse (1885), Sophocles: The plays and fragments: The Oedipus Coloneus, vol. 2. Cambridge.

Jouan, François \& Van Looy, Herman (1998), Euripide. Fragments (tome VIII). Paris. Kamerbeek, Jan Coenraad (1980), The plays of Sophocles: The Oedipus Coloneus. Leiden. Kannicht, Richard (2004), Tragicorum Graecorum Fragmenta, vol. 5. Göttingen.

Lloyd-Jones, Hugh \& Wilson, Nigel (1990), Sophoclis fabulae. Oxonii.

Pearson, Alfred C. (1924), Sophoclis fabulae. Oxonii.

\section{Bibliografía secundaria}

Beer, Josh (2004), Sophocles and the tragedy of Athenian democracy. Westport (Connecticut). Birge, Darice (1982), Sacred groves in the ancient Greek world. Berkeley.

- (1984), «The grove of the Eumenides: refuge and hero shrine in Oedipus at Colonus», CJ 80 (1), 11-17.

Bowra, Cecil Maurice (1944), Sophoclean tragedy. London, Oxford.

Burkert, Walter (2007), Religión griega: arcaica y clásica. Madrid (trad. esp.).

Burton, Reginald William Boteler (1980), The chorus in Sophocles'tragedies. Oxford.

Gardiner, Cynthia P. (1987), The Sophoclean chorus: a study of character and function. Iowa City.

Hulton, A. O. (1969), «The prologues of Sophocles», G\&R 16 (1), 49-59.

Jouanna, Jacques (1995), «Espaces sacrés, rites et oracles dans l'Edipe à Colone de Sophocle», REG 108 (1), 38-58.

Knox, Bernard M. W. (1964), The heroic temper: studies in Sophoclean tragedy. Berkeley, Los Angeles, London.

Mauduit, Christine (1988), «Le sauvage et le sacré dans la tragédie grecque», $B A G B 47$ (4), 303-317.

McDevitt, Arthur S. (1972), «The nightingale and the olive», en Hanslik, R. \& Lesky, A. \& Schwabl, H. \& Kraus, W. (eds.), Antidosis, Festschrift für Walther Kraus 5, Wien, 229-237.

Nestle, Walter (1967), Die Struktur des Eingangs in der attischen Tragödie. Hildesheim.

Palomar, Natalia (1999), «El héroe trágico de Sófocles: imágenes del dolor humano», Habis 30, 57-76.

Parke, Herbert William (1986), Festivals of the Athenians. London.

Roberts, Deborah H. (2006), «Beginnings and endings», en Gregory, Justina (ed.), A companion to Greek tragedy, Malden, Oxford, Carlton, 136-148.

Rodighiero, Andrea (2012), «The sense of place: Oedipus at Colonus, political geography and the defence of a way of life», en Markantonatos, Andreas \& Zimmermann, Bernhard (eds.), Crisis on stage: tragedy and comedy in late fifth-century Athens, Berlin, 55-80.

Schmidt, Hans W. (1971), «Die Struktur des Eingangs», en Jens, Walter (ed.), Die Bauformen der Griechischen Tragödie, München, 1-46.

Saïd, Suzanne (2012), «Athens and Athenian space in Oedipus at Colonus», en Markantonatos, Andreas \& Zimmermann, Bernhard (eds.), Crisis on stage: tragedy and comedy in late fifth-century Athens, Berlin, 81-100. 
Segal, Charles (1999), Tragedy and civilization: an interpretation to Sophocles. Norman.

Vernant, Jean Pierre (2002), «Ambigüedad e inversión. Sobre la estructura enigmática del Edipo Rey», en Vernant, Jean Pierre \& Vidal-Naquet, Pierre (eds.), Mito y tragedia en la Grecia antigua, vol. 1, Barcelona (trad. esp.), 103-135.

Wallace, Nathaniel O. (1979), «Oedipus at Colonus: the hero and his collective context», QUCC 3, 39-52.

Winnington-Ingram, Reginald Pepys (1980), Sophocles: An interpretation. Cambridge. 